\title{
Ultrasound and stethoscope as tools in medical education and practice: considerations for the archives
}

\section{Francis A Fakoya \\ Maira du Plessis \\ Ikechi B Gbenimacho}

Department of Anatomical Sciences, St George's University School of Medicine, St George's University, Grenada, West Indies

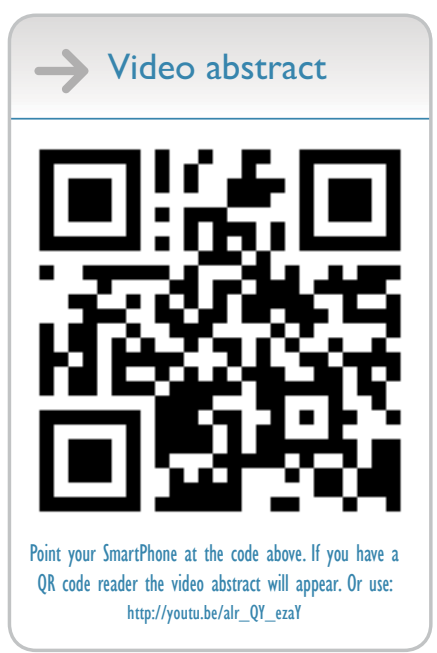

Correspondence: Francis A Fakoya Department of Anatomical Sciences, St George's University School of Medicine, St George's University, PO Box 7, True Blue Campus, St George's, Grenada, West Indies Tel +I 4734444175 (extension 38I7) Email ffakoya@sgu.edu
This article was published in the following Dove Press journal:

Advances in Medical Education and Practice

13 July 2016

Number of times this article has been viewed

Objectives: In recent years, the use and portability of ultrasound has threatened the utility of the stethoscope, with many debating and even advocating its replacement. The authors set out to assess opinions in this regard among faculty within a medical school and specifically within an anatomy department where ultrasound is incorporated into the curriculum from the first term. Methods: A debate was elicited during a biweekly Anatomy Journal Club session and was centered on three published papers presented. Several questions were raised regarding the possible replacement of stethoscope - the value of early exposure to students as well as how ultrasound and stethoscope should be considered by physicians, students, and teachers.

Results: The general consensus was that the stethoscope should not be replaced but should be used in conjunction with emerging portable ultrasound. Caution was given that technology could "overcomplicate" diagnosis and lead to increased tests resulting in increased cost of care. In terms of exposing students to ultrasound, just as the stethoscope requires practice to use effectively, so does the ultrasound and should be introduced as early on as possible. As is the case with the stethoscope, students may not initially appreciate all the finer details on ultrasound; however, continual use would improve skill.

Conclusion: The stethoscope should always remain part of the physical examination and ultrasound should be used in addition to, not replacement of. As technology advances the need for apprenticeship, training increases and students of the medical profession should be exposed to these technologies as early as possible. Hence, it is not yet time to archive the stethoscope. Perhaps never.

Keywords: ultrasound technology, stethoscope, gross anatomy, physical examination, clinical skills, medical education

\section{Introduction}

With development of new technologies in medical science, one is often tempted to replace age-old trusted techniques and equipment in favor of the new. The same is true with the training of medical students and continuous changing curriculum. In recent years, with the increased accessibility to ultrasound (portable ultrasound), some arguments have been raised in favor of replacing the traditional stethoscope with ultrasound during physical examination.

The stethoscope is an acoustic medical device for auscultation of an animal or human body, often used to listen to lung and heart sounds. It can also be used to listen to intestines and blood flow in arteries and veins, and commonly in combination with a sphygmomanometer, it is used in the measurement of blood pressure. It is familiar, 
harmless, portable, and inexpensive, but the sound heard through the stethoscope depends on three main factors: actual sound (vibrations) produced by organs, perception of sound by the human ear (psychoacoustics), and acoustics of the stethoscope itself. ${ }^{1}$ The principle of stethoscope was first applied in the 19th century by Rene Theophile Hyacinthe Laënnec, a French physician, who in 1816 invented the stethoscope $^{2-6}$ as an experimental creation to avoid an embarrassing situation while examining a female patient. ${ }^{6}$ Using this new instrument, he investigated the sounds made by the heart and lungs and established that his diagnoses were supported by the observations made during autopsies. ${ }^{7,8}$ Despite its late invention, the importance of listening to a patient's chest was first noted in $370 \mathrm{BC}$ by Hippocrates and described by two others prior to the invention of the stethoscope. ${ }^{8}$ It has since undergone several modifications with the noteworthy inventions of the diaphragm by Rober Bowles (1926) and the bell in 1961 by Lithmann ${ }^{8}$ with many different types including the electronic one existing today. ${ }^{7}$ Over the years, stethoscope has become more than just a tool used for examination but serves as a symbol of identity associated with the physician. ${ }^{2,3}$

Over the past five decades, ultrasound has become an important diagnostic modality. Its potential in medical diagnostic imaging was recognized in the 1930s and 1940s, when Theodore Dussik and his brother Friederich attempted to use ultrasound to diagnose brain tumors. ${ }^{9}$ It was not until the 1970s, however, that the work of these and other pioneers of ultrasound research truly came to fruition. With technological advances, ultrasound has progressed from a large, cumbersome machine producing suboptimal images to a portable, user-friendly and sophisticated instrument. Such evolution has required the collaboration of physics, physiology, medicine, engineering, and government and has resulted in the integration of ultrasound into everyday clinical practice. ${ }^{10}$ Ultrasonography has found increasing use in several medical specialties such as anesthesiology, intensive care, emergency medicine, surgery, obstetrics and gynecology, and internal medicine $e^{10-15}$ that have led to the introduction of the term "point-of-care-ultrasound". ${ }^{16-18}$

Some medical schools have incorporated ultrasound into their undergraduate medical curriculum, ${ }^{19,20}$ a teaching modality currently being explored in anatomy, ${ }^{21,22}$ physiology, ${ }^{23}$ pathology, and clinical skills. Studies have found ultrasound as a helpful educational resource with high student satisfaction for teaching cardiovascular and renal anatomy, ${ }^{24-26}$ demonstrating organs and investigating forearm muscles and vasculature. ${ }^{27}$ It is reported that using cadavers and imaging together improves the students' abil- ity to identify anatomical structures and provides long-term knowledge retention. ${ }^{28}$

The Department of Anatomical Sciences at St George's University, Grenada, recently introduced ultrasound as part of the anatomy curriculum, exposing students in their first term of medical school to 16 hours of ultrasound demonstration and practice on standardized patients (SPs) alongside wet labs, physical examination sessions, and simulated patients. Many questions have been raised sequel to this addition, most of which are based on the appropriateness of teaching preclinical students to use ultrasound as well as the possible replacement of stethoscopes with portable ultrasound devices. ${ }^{29}$ Arguments for and against this have been equally strongly motivated in the literature. ${ }^{6,17,30-35}$

The aim of this communication was, therefore, to express the views and opinions of the members of faculty in a debate on this topic elicited during a journal club meeting.

\section{Methods}

As ultrasound forms a substantial component of the anatomy course offered at St George's University, Grenada, a debate was elicited during a biweekly Anatomy Journal Club (AJC) session titled "Ultrasound: Stethoscope of the 21 st Century" on October 25, 2012. In attendance at this session was a crosssection of faculty from the schools of medicine, veterinary medicine, and arts and sciences, following a wide invitation to all faculty, staff, and students, to broaden the range of audience participation. During the AJC session, three papers were presented (Gillmam and Kirkpatrick, 2012 ${ }^{17}$; Filly, 1988 ${ }^{36}$; Brenner, 2010 ${ }^{37}$ ) and the session was followed by a moderated-focus group discussion based on the following questions:

1. Can stethoscopes be replaced by ultrasound?

2. If ultrasound is the stethoscope of the future, how then should we be training the physicians of tomorrow?

3. Where and when should this training be and by whom? Can the students handle the tool for effective use?

4. What is the impact of this new paradigm shift on clinical skills, clinical reasoning, clinical acumen, and clinical practice?

5. How do we address these issues?

The AJC is a formalized meeting structure and process that began in 2010 to teach critical appraisal skills and to develop and facilitate lifelong learning and presentation skills for all academic members of the Department of Anatomical Sciences, in particular for junior faculty and clinical tutors. The AJC also supports members to keep up with scientific literature, 
demonstrate continuing anatomy education, and stimulate interest in research. Institutional Review board approval was not required for this session being a regular academic activity of the department, as acknowledged by all participants; there being no potential harm to the participants; anonymity was guaranteed; and the participants consented to participate in the session.

\section{Results and discussion}

Miniaturization and advanced digital techniques have resulted in the development of high-resolution, battery-powered personal ultrasound devices with excellent gray-scale and color blood flow imaging capabilities. These devices have extended the physical perception of clinical examination by "seeing the invisible pathology" and allow the user to address specific clinical problems anywhere at the point-of-care. ${ }^{17,35}$ The device can effectively assist in the initial evaluation and rapid diagnosis of potentially life-threatening conditions or in situations where quick decision-making is essential. They strengthen the clinical diagnostic accuracy and may also add quantitative information. Yet, do these qualities warrant the rejection, archival, and complete replacement of the traditional stethoscope with this new device that has been referred to as the "ultrasound stethoscope"?

\section{Can stethoscopes be replaced by ultrasound?}

The ultimate objective of medical education is the training of compassionate, empathetic, and objective physicians able to arrive at accurate diagnosis essential for effective treatment. After history taking, physical examination is second in importance in assessing a patient. The time-honored sequence of inspection, palpation, percussion, and auscultation derives from the 19th-century methods of clinical examination and has been the basis for most diagnoses. ${ }^{38}$ However, today's world of imaging techniques and other technologies has created a challenge for teachers to decide on the old techniques that are worthy of preservation. ${ }^{4}$ Diagnostic tests are becoming more complex, more expensive, and more inclined to separate the patient and physician, yet stethoscope has remained the most commonly used diagnostic medical instrument, even though it is not always used to best advantage. ${ }^{38}$ Improvements in sound recording and analysis techniques have spurred a renewed interest in lung sounds and their meaning. This is likely to lead to better understanding of what we hear, and perhaps to the development of new noninvasive diagnostic and monitoring techniques. ${ }^{38}$

Ultrasound is safe and has the advantage of providing visualization of structures and their movement in a noninvasive manner. The advent of high-quality, portable equipment has enabled the dissemination of ultrasound technology to the bedside physician. Led by a few pioneers, the development and applications of diagnostic ultrasound are occurring in a variety of settings, including bedside medical-surgical care, ambulatory clinics, and medical education. ${ }^{39,40}$ Ultrasound has evolved rapidly in the past few decades as an imaging modality and comprises almost $25 \%$ of imaging worldwide. ${ }^{23,41,42}$ The safe performance of procedures is an important part of both medical education and medical practice. On the account of "....... do no harm to my patient....." of the Hippocratic oath of the physician, both the stethoscope and ultrasound are safe and valuable instruments in the physical examination of patients, which remains very vital in arriving at a good differential diagnosis. The use of both the stethoscope and ultrasound no doubt will increase the physician's efficiency and accuracy in performing a physical examination and forming a diagnosis, respectively. ${ }^{17,29}$ While the superiority of USS is well recognized in cardiac evaluation, ${ }^{17}$ stethoscope will always remain in use. The analogy was made with X-rays. Even though the technology is considered "old fashioned," and imaging techniques such as magnetic resonance imaging (MRI) and computed tomography (CT) are available, it is still "at the frontline of medicine." The combined use of ultrasound and stethoscope is promoted. The use of electronic sounds as an adjunct to ultrasound which is currently available may "overcomplicate" the medical examination and, therefore, the diagnosis.

In recent years, the use of ultrasound has improved the safety of key procedures including central venous catheter placement and thoracocentesis. ${ }^{43}$ Being a completely safe noninvasive imaging technique, it has advantages over other imaging modalities in terms of availability and comfort, safety, and diagnostic potential. Operating costs are low compared to both CT and MRI. In contrast to CT and X-rays, it does not emit ionizing radiation. Unlike MRI, it is safe for all patients, including those with cardiac pacemakers and metal implants. ${ }^{44}$ Importantly, ultrasonography is performed while patients lie in a comfortable position, without pain or claustrophobia, and it enhances the early detection of pathologies. Its high resolution enables the detection of tendon tears, tiny calcifications, and foreign bodies. ${ }^{44}$ Calcification in soft tissue and destructive and reparative hypertrophic changes on bone surfaces are more readily apparent with ultrasonography, and at an earlier stage, than with plain X-rays, CT, or MRI. ${ }^{44}$ The portable equipment is accessible at locations distant from medical centers. 
The quality of the diagnostic image is of utmost importance and is the end product of a combination of many factors originating not only from the imaging system, including the transducer, the electronics, image processing, display, and recording devices, but also from the performance of the operator. This was highlighted by the following statementthe very best of equipment used by an unskilled operator will generate poor quality images, as will unsatisfactory equipment in the hands of a highly qualified operator. ${ }^{43} \mathrm{To}$ this end, ultrasound does not appear to be in a position to replace stethoscope, especially because they give different aspects of the same examination. Importantly, there is a tendency that ultrasound used as a physical examination tool might overcomplicate diagnosis and potentially lead to unnecessary tests something that has been supported by others. ${ }^{45}$ Despite its portable nature and availability, thanks to technology, the simple ultrasound handheld device is still far more expensive than a stethoscope, a fact that undermines universal health care. ${ }^{36}$

\section{How realistic is teaching first-year/ first-term medical students to use ultrasound?}

Simply put, the majority of individuals at the debate agreed that this is good practice showing that the need for apprenticeship greatly outweighs the concerns about overloading students. Not only does this allow them to get familiar with the equipment but also it enhances their knowledge and understanding of anatomy and pathology. This position is supported by the report of Royse et al (2012) who suggested that the evolution should start at the medical-student level and be reinforced throughout specialist training. ${ }^{10}$ The key to making ultrasound available to every physician is through education programs designed to facilitate uptake rather than to prevent access to this technology and education by specialist craft groups. While it was noted from several reports that there is a drive to integrate ultrasound formally in the undergraduate medical curriculum, in particular in North America, ${ }^{19-26}$ and that ultrasonography helps to promote students' interest in traditional preclinical subjects such as anatomy, pathology, and physiology and improves medical students' ability to perform physical examination, as well as their diagnostic accuracy using an US-augmented physical examination, a major drawback of this drive is the compromise of the time required for traditional preclinical courses for medical students who already experience heavy coursework and classroom time. Because ultrasound use requires the development of psychomotor skills, a low student-instructor ratio of $4: 1$ is necessary to ensure adequate practice. ${ }^{19}$ This raised further issues such as the following:

1. The lack of minimum standardized curriculum for ultrasound for both undergraduate and graduate programmes. ${ }^{12,26}$

2. The requirement of time and low faculty/student ratio for effective teaching/learning.

3. How critical is it to include ultrasound in examinations? If the anatomy course is not assessed, how much attention will the students appropriate to it?

4. How relevant is this knowledge with regards to the various medical board examinations?

5. Has any regulatory body mandated a minimum core competence in ultrasound for medical students?

The session averred, however, that the most appropriate adjunct for ultrasound learning is SPs instead of peer participation. SPs are typically healthy individuals with few or no abnormal physical findings used in medical education to teach and assess communication and clinical skills. The limitation is that each SP can only portray a limited set of physical symptoms. ${ }^{46}$

\section{Where and when should this training be and by whom? Can the students handle the tool for effective use?}

The integration of ultrasound into medical education must be done responsibly following well-constructed process, objectives, and availability of resources and expertise to teach the technique. ${ }^{47}$ Like using the stethoscope, ultrasound use is also operator dependent, requiring practice and expertise to develop appropriate techniques and skills. ${ }^{17}$ Thus, the extent to which the technology is put to use will be the extent to which it remains functional. The primary objective of training students across disciplines is on how to broaden - rather than deepen - their knowledge and how to couple their knowledge with intellectual curiosity, critical thinking, creativity, moral courage, and responsibility. Medicine is an art; just as it takes time to learn how to use a stethoscope, it also takes time to learn the use of ultrasound. Hence, the longer the students are exposed to it the better they are in terms of apprenticeship training and practice. Education should change and adapt with the changes in practice; even if the students cannot appreciate the finer details on ultrasound image, it still helps them being exposed to it early. However, overreliance on ultrasound technology may erode interest and enthusiasm for teaching and using those physical examination skills, including stethoscope, that are still clinically essential. 
This would be regrettable, as it would deprive clinicians of an essential filter (and guidance) for the proper use and interpretation of the laboratory tests. Because unnecessary tests beget more tests, the loss of such a filter might raise costs of care and possibly harm patients. ${ }^{45}$

\section{What is the impact of this new paradigm shift on clinical skills, clinical reasoning, clinical acumen, and clinical practice?}

Using a stethoscope for auscultation offers an opportunity for the clinician and patient to establish a rapport that goes beyond what can be established by conversation. Auscultation is a time when the examiner invades the patient's intimate space and touches him/her in a caring but professional manner. ${ }^{48}$ It has been reported that most patients appreciate this time of bonding and relationship-building, in which trust and confidence are established. Patients often forget components of the interview but usually remember an examiner's proper use of touch and careful examination. ${ }^{49}$ The ultrasound examination does not offer this unique opportunity, since the patient is able to "see" his/her internal space - often associated with a sense of anxiety and even fear for the unknown. ${ }^{50}$

The stethoscope represents the physician more than any other symbol, 2,3,13 except perhaps the shaft of Asclepius of Kos Island - the god of Temple medicine of the Greek antiquity - Greece (birthplace of Hippocrates). It was a remarkable addition to the clinico-diagnostic armamentarium of doctors that has undergone a long march of continuous innovative development supplying the demand for a relevant auscultatory bedside tool to examine different medical conditions ${ }^{3}$ and remain an important part of medical culture. ${ }^{17,34}$

The stethoscope has the enormous advantage of being so simple an instrument. The name "stethoscope" is from two Greek words meaning "the chest" and "to examine". 6 In conclusion, we can say that Laennec's stethoscope, an instrument in itself of the utmost simplicity (although its use has always demanded skill, patience, and close study), has had and still continues to have a profound effect on medicine. Sir James Kingston Fowler of the Brompton Hospital once wrote: Those who advise that all stethoscopes should be "scrapped" may be influenced by the fact that they do not know how to use their own - A stethoscope is easier to carry than a cardiograph or X-ray installation ... Neither are common in the "bushstations" of West Africa. ${ }^{45}$

As the stethoscope does not rely on electricity or batteries, it will never be replaced, and hence there is a strong need to rekindle interest and competence in essential bedside skills like auscultation. This renewal will require time and effort. Some clinicians may not utilize (or teach) physical diagnosis because they are unsure of their own skills. ${ }^{45}$ Thus, medical school faculty need time not only to teach physical diagnosis but also to relearn it when necessary. With increasing emphasis on objective measurement of physicians' bedside skills at the time of internal medicine recertification, this task might even become a timely area for future faculty development.

Technology is fast moving and changing rapidly, and one should keep an open mind about it and be prepared to adapt. Some nonhabitual asymptomatic metabolic diseases have warning signs that can be recognized early using ultrasound. It should thus be used in combination with the stethoscope, as early detection and treatment can prevent the development of end-stage complications.

\section{In conclusion, how do we address these issues?}

Ultrasound scanning is a new universal medical tool that may be compared to a stethoscope. Both are highly operatordependent examinations used for screening and both should be followed by more conclusive examinations. The use of ultrasound and exposure of medical students to this at an early stage in their training is part of the modernizing of medical education to adjust to new technologies being developed constantly as part of medical practice. We would like to reecho the words of Dr Herrick in an address before the American College of Physicians in 1930, when he gave a passionate "plea for the sane use of every means that may help in diagnosis, including the stethoscope and all that it stands for in the way of physical diagnosis. Physical examination should not yet be regarded as displaced by other methods. It still has a legitimate function. Undergraduates and practitioners should still be taught its theory and its practice so that it may not become a lost art". ${ }^{51}$ These words are as valid today as they were 85 years ago.

\section{Conclusion}

- The safe performance of procedures is an important part of both medical education and medical practice.

- Both ultrasound and stethoscope are highly operatordependent examinations tools used for screening, and both should be followed by more conclusive examinations.

- Despite its portable nature and availability, thanks to technology, the simple ultrasound handheld device is still far more expensive than a stethoscope, a fact that undermines universal health care. 
- The integration of ultrasound into medical education must be done responsibly following well-constructed processes, objectives, and availability of resources and expertise to teach the technique.

- As the stethoscope does not rely on electricity or batteries it will never be replaced; hence, there is a strong need to rekindle interest and competence in essential bedside skills like auscultation.

\section{Acknowledgment}

We appreciate and thank all the faculty of the schools of medicine, veterinary medicine, and arts and science who participated and contributed to the debate during the AJC session conducted on October 25, 2012.

\section{Author contributions}

Francis A Fakoya is professor of anatomy, histology, and cell biology at the Department of Anatomical Sciences, $\mathrm{St}$ George's University School of Medicine. As a coordinator of the AJC, he conceptualized, designed, organized, and facilitated the methodology as well as moderated the debate that is being reported and wrote the final manuscript submitted.

Maira du Plessis is an instructor in anatomy within the Department of Anatomical Sciences. She took part in the debate that the paper is based on during which she served as the rapporteur. She contributed to and discussed the viewpoints raised during the debate with the other authors and wrote and revised the manuscript.

Ikechi Bright Gbenimacho is a clinical instructor in anatomy within the Department of Anatomical Sciences. He participated in the debate and discussion upon which the paper is based and contributed to the manuscript's literature review on the history of ultrasound and its diagnostic importance. All authors contributed toward data analysis, drafting and revising the paper and agree to be accountable for all aspects of the work.

\section{Disclosure}

The authors report no conflict of interest in this work.

\section{References}

1. Welsby PD, Earis JE. Some high pitched thoughts on chest examination. Postgrad Med J. 2001;77(912):617-620.

2. Roguin AR. Theophile Hyacinthe Laënnec (1781-1826): the man behind the stethoscope. Clin Med Res. 2006;4(3):230-235.

3. Majumdar SK. History of the stethoscope an overview. Bull Indian Inst Hist Med Hyderabad. 2002;32(2):137-150.

4. Demetriades AK. Laennec's legacy. J R Soc Med. 2004;97(5):257-258.

5. Dalmay F, Antonini MT, Marquet P, Menier R. Acoustic properties of the normal chest. Eur Respir J. 1995;8(10):1761-1769.
6. Bishop PJ. Evolution of the stethoscope. J R Soc Med. 1980; 73(6):448-456.

7. Weinberg FW. The history of stethoscope. Can Fam Physician. 1993; 39:2223-2224.

8. Mangion K. The stethoscope. MMJ. 2007;19(2):41-44.

9. Newman PG, Rozycki GS. The history of ultrasound. Surg Clin North Am. 1998;78(2):179-195.

10. Royse CF, Canty DJ, Faris J, Haji DL, Veltman M, Royse A. Core review: physician-performed ultrasound: the time has come for routine use in acute care medicine. Anesth Analg. 2012;115(5):1007-1028.

11. Moore DL, Ding L, Sadhasivam S. Novel real-time feedback and integrated simulation model for teaching and evaluating ultrasound-guided regional anesthesia skills in pediatric anesthesia trainees. Paediatr Anaesth. 2012;22(9):847-853.

12. Kimura BJ, Amundson SA, Phan JN, Agan DL, Shaw DJ. Observations during development of an internal medicine residency training program in cardiovascular limited ultrasound examination. J Hosp Med. 2012;7(7):537-542.

13. Tamborrini G, Krebs A, Michel M, Michel BA, Ciurea A. [Web-based learning in musculoskeletal ultrasound]. Z Rheumatol. 2011;70(2): 154-159. German.

14. Kessler C, Bhandarkar S. Ultrasound training for medical students and internal medicine residents - a needs assessment. J Clin Ultrasound. 2010;38(8):401-408.

15. Mandavia DP, Aragona J, Chan L, Chan D, Henderson SO. Ultrasound training for emergency physicians - a prospective study. Acad Emerg Med. 2000;7(9):1008-1014.

16. Coşkun F, Akıncı E, Ceyhan MA, Sahin Kavaklı H. Our new stethoscope in the emergency department: handheld ultrasound. Ulus Travma Acil Cerrahi Derg. 2011;17(6):488-492.

17. Gillmam LM, Kirkpatrick AW. Portable bedside ultrasound: the visual stethoscope of the 21st century. Scand J Trauma Resusc Emerg Med. 2012;20:18.

18. Amiel JB, Grümann A, Lhéritier G, et al. Assessment of left ventricular ejection fraction using an ultrasonic stethoscope in critically ill patients. Crit Care. 2012;16(1):R29.

19. Fox JC, Chiem AT, Rooney KP, Maldonaldo G. Web-based lectures, peer instruction and ultrasound-integrated medical education. Med Educ. 2012;46(11):1109-1110.

20. Hoppmann RA, Rao VV, Poston MB, et al. An integrated ultrasound curriculum (iUSC) for medical students: 4-year experience. Crit Ultrasound J. 2011;3(1):1-12.

21. Swamy M, Searle RF. Anatomy teaching with portable ultrasound to medical students. BMC Med Educ. 2012;12(99):1-4.

22. Brown B, Adhikari S, Marx J, Lander L, Todd GL. Introduction of ultrasound into gross anatomy curriculum: perceptions of medical students. J Emerg Med. 2012;43(6):1098-1102.

23. Omoto K, Kawano M, Yamada T, et al. Educational courses for physiological function examination at Jichi Medical University: practical trainings in ultrasonography. Rinsho Byori. 2011;59(8):776-780.

24. Wong I, Jayatilleke T, Kendall R, Atkinson P. Feasibility of a focused ultrasound training programme for medical undergraduate students. Clin Teach. 2011;8(1):3-7.

25. Tshibwabwa ET, Groves HM. Integration of ultrasound in the education programme in anatomy. Med Educ. 2005;39:1143-1172.

26. Bessmann EL, Bitsch M. [Medical students gain from a practical course in clinical ultrasound]. Ugeskr Laeger. 2012;174(48):3000-3003. Danish.

27. Heilo A, Hansen AB, Holck P, Laerum F. Ultrasound 'electronic vivisection' in the teaching of human anatomy for medical students. Eur J Ultrasound. 1997;5:203-207.

28. Miles KA. Diagnostic imaging in undergraduate medical education: an expanding role. Clin Radiol. 2005;60(7):742-745.

29. Murphy RLH. In defense of the stethoscope. J Resp Care. 2008; 53(3):355-369.

30. Cabalag C. The ultrasound of things to come. J Mob Technol Med.2012; $1(1): 5-7$. 
31. Lisi M, Cameli M, Mondillo S, et al. Incremental value of pocket-sized imaging device for bedside diagnosis of unilateral pleural effusions and ultrasound-guided thoracentesis. Interact Cardiovasc Thorac Surg. 2012;15(4):596-601.

32. Sporen I. Ultrasound use in obstetric. J Med Ultrasound. 2012;14(1).

33. Galderisi M, Santoro A, Versiero M, et al. Improved cardiovascular diagnostic accuracy by pocket size imaging device in non-cardiologic outpatients: the NaUSiCa (Naples Ultrasound Stethoscope in Cardiology) study. Cardiovasc Ultrasound. 2010;8:51.

34. Dolara A. The decline of cardiac auscultation: 'the ball of the match point is poised on the net'. J Cardiovasc Med (Hagerstown). 2008;9(11):1173-1174.

35. Roelandt JR. Ultrasound stethoscopy. Eur J Intern Med. 2004; 15(6):337-347.

36. Filly RA. Is it time for the sonoscope? If so, then let's do it right! J Ultrasound Med. 2003;22(4):323-325.

37. Brenner DJ. Medical imaging in the 21 st century - getting the best bang for the Rad. N Engl J Med. 2010;362(10):943-945.

38. Loudon RG. The lung exam. Clin Chest Med. 1987;8(2):265-272.

39. Rao S, van Holsbeek L, Musial JL, et al. A pilot study of comprehensive ultrasound education at Wayne State University School of Medicine: a pioneer year review. J Ultrasound Med. 2008;27(5):745-749.

40. Hoppmann R, Cook T, Hunt P, et al. Ultrasound in medical education: a vertical curriculum at the University of South Carolina School of Medicine. J S C Med Assoc. 2006;102(10):330-334.
41. Wells PNT. Ultrasound imaging. Phys Med Biol. 2006;51:R83-R98.

42. Shapiro RS, Ko PP, Jacobson S. A pilot project to study the use of ultrasonography for teaching physical examination to medical students. Comput Biol Med. 2002;32:403-409.

43. Chan V, Perlas A. Basics of ultrasound imaging. In: Narouze SN, editor. Atlas of Ultrasound Guided Procedures in Interventional Pain Management. Germany: Springer Science+Business Media LLC; 2011;13-19.

44. Blankstein A. Ultrasound in the diagnosis of clinical orthopedics: the orthopedic stethoscope. World J Orthop. 2011;2(2):13-24.

45. Weitz HH, Mangione S. In defense of the stethoscope and the bedside. Am J Med. 2000;108(8):669-671.

46. Sun B, McKenzie FD, Garcia HM, Hubbard TW, Ullian JA, Gliva GA. Medical student evaluation using augmented standardized patients: new development and results. Stud Health Technol Inform. 2007;125:454 456.

47. Fakoya FA. Integrating ultrasound technology into teaching gross anatomy: point of order! Med Educ Online. 2013;18:20888.

48. Wilkins RL. Preparing for the patient encounter. In: Wilkins RL, Krider SJ, Sheldon RL, editors. Clinical Assessment in Respiratory Care. 4th ed. St Louis: Mosby; 2000;2-14

49. Nardone DA, Lucas LM, Palac DM. Physical examination: a revered skill under scrutiny. South Med J. 1988;81(6):770-773.

50. Wilkins RL. Is the stethoscope on the verge of becoming obsolete? Respir Care. 2004;49(12):1488-1489.

51. Herrick JB. In defense of the stethoscope. Ann Intern Med. 1930; 4:113-116.
Advances in Medical Education and Practice

\section{Publish your work in this journal}

Advances in Medical Education and Practice is an international, peerreviewed, open access journal that aims to present and publish research on Medical Education covering medical, dental, nursing and allied health care professional education. The journal covers undergraduate education, postgraduate training and continuing medical education

\section{Dovepress}

including emerging trends and innovative models linking education, research, and health care services. The manuscript management system is completely online and includes a very quick and fair peer-review system. Visit http://www.dovepress.com/testimonials.php to read real quotes from published authors. 